Int. J. Dev. Biol. 48: 327-332 (2004)

Original Article

\title{
Activin-like signaling activates Notch signaling during mesodermal induction
}

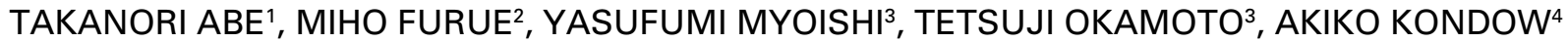 \\ and MAKOTO ASASHIMA*,1,4,5
}

${ }^{1}$ Department of Biological Science, Graduate School of Science, The University of Tokyo, Japan ${ }^{2}$ Department of Biochemistry and Molecular Biology, Kanagawa Dental College, Yokosuka, Japan ${ }^{3}$ Department of Molecular Oral Medicine and Maxillofacial Surgery, Division of Frontier Medical Science, Graduate School of Biomedical Sciences, Hiroshima University, Japan, ${ }^{4}$ Department of Life Sciences (Biology), Graduate School of Arts and Sciences, Japan and ${ }^{5}$ SORST/Japan Science and Technology Corporation, The University of Tokyo, Japan

\begin{abstract}
Both activin-like signaling and Notch signaling play fundamental roles during early development. Activin-like signaling is involved in mesodermal induction and can induce a broad range of mesodermal genes and tissues from prospective ectodermal cells (animal caps). On the other hand, Notch signaling plays important roles when multipotent precursor cells achieve a specific cell fate. However, the relationship between these two signal pathways is not well understood. Here, we show that activin A induces Delta-1, Delta-2 and Notch expression and then activates Notch signaling in animal caps. Also, in vivo, ectopic activin-like signaling induced the ectopic expression of Delta-1 and Delta-2, whereas inhibition of activin-like signaling abolished the expression of Delta-1 and Delta-2. Furthermore, we show that $M y o D$, which is myogenic gene induced by activin A, can induce Delta-1 expression. However, MyoD had no effect on Notch expression, and inhibited Delta-2 expression. These results indicated that activin A induces Delta1, Delta-2 and Notch by different cascades. We conclude that Notch signaling is activated when activin-like signaling induces various tissues from homogenous undifferentiated cells.
\end{abstract}

KEY WORDS: Xenopus laevis, activin, Notch signaling, MyoD, mesoderm induction

\section{Introduction}

Activin A, a member of the TGF- $\beta$ family, which has a strong mesoderm-inducing activity (Asashima etal., 1990), can induce a broad range of mesodermal genes and tissues from amphibian prospective ectodermal cells (animal caps) in a concentration-dependent manner (Ariizumi et al., 1991a; Ariizumi et al., 1991b; Green and Smith, 1990). At low concentrations, activin $A$ induces the formation of ventral and posterior mesodermal tissues such as blood cells, coelomic epithelium and mesenchyme. At intermediate concentrations, activin A induces muscle, and at high concentrations, it induces dorsal and anterior mesoderm tissues such as notochord, and yolk-loaded endoderm. In addition, activin $\mathrm{A}$ in combination with retinoic acid induces pronephros (Brennan et al., 1999; Moriya et al., 1993; Osafune et al., 2002) and anterior endoderm tissues such as pancreas (Moriya et al., 2000), liver, and intestine. Furthermore, activin A can also induce beating heart muscle (Ariizumi et al., 1996) and jaw cartilage (Furue et al., 2002) by the sandwich-culture method. Notch encodes a large transmem- brane protein that serves as a receptor for the Delta, Serrate, and Lag-2 (DSL) family of ligands. Binding of a DSL ligand to the extracellular domain of Notch causes cleavage of the receptor's intracellular domain, which is then released from the cell membrane (De Strooper et al., 1999; Mumm et al., 2000). The intracellular domain of Notch translocates into the nucleus, where it can interact with members of the CBF-1, Suppressor of Hairless, Lag-1 (CSL) family. The complex of DSL and the intracellular domain of Notch subsequently activates the expression of target genes, such as ESR, Hairy, and Hey (Bailey and Posakony, 1995; Lecourtois and Schweisguth, 1995; Leimeister et al., 1999; Tannahill et al., 1995). Notch signaling is involved in multiple developmental processes and controls the cell-fate decision by regulating local cell-cell communication (Artavanis-Tsakonas et al., 1999). Notch signaling main-

Abbreviations used in this paper: ALK4 dn, dominant negative activin receptorlike kinase 4; AR1, activin type II receptor; DSL, Delta, Serrate and Lag2 ligand family; ODC, ornithine decarboxylase.

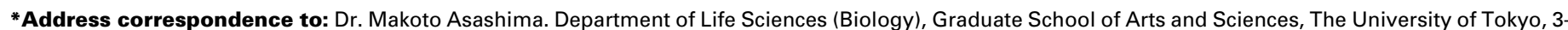
8-1 Komaba, Meguro-ku, Tokyo, 153-8902, Japan. Fax: +81-3-5454-4330. e-mail: asashi@bio.c.u-tokyo.ac.jp
} 
tains precursor cells in an undifferentiated state, and allows cells within a multipotent precursor population to achieve a specific cell fate during development (Hitoshi et al., 2002). Furthermore, Notch signaling regulates the cytodifferentiation of myogenesis, pronephric duct, pronephric tubules, pancreatic cells, and heart (Apelqvist et al., 1999; Delfini et al., 2000; McCright et al., 2001; McLaughlin et al., 2000; Nofziger et al., 1999; Rones et al., 2000).

We are interested in the tissues whose differentiation is regulated by Notch signaling because activin A predominantly induces the same range of tissues in animal caps. In Xenopus embryos, Delta-1 and Delta-2 are expressed from gastrulation onward in the ring around the blastopore. Notch expression is higher in dorsal mesoderm, although Notchexpression is relatively uniform throughout the embryo (Coffman et al., 1990). These expression regions of members of Notch-signaling pathway genes seem to be overlapping the region where activin-like signaling induces mesoderm. From these findings, we speculated that the activin-like signaling and Notch signaling pathways interact at the stage during which activin-like signaling induced various tissues from homogenous undifferentiated cells in early Xenopus development, in particular during mesoderm induction. In this study, we demonstrate that activin A can induce Notch-signal pathway genes in a concentration-dependent manner and activate Notch signaling in animal caps. Also in vivo, activin-like signaling controls Delta-1 and Delta-2 expression. Furthermore, we show that activin A induced Delta-1, Delta-2 and Notch by a different cascade.

\section{Results}

\section{Activin A induces the transcription of Notch-signaling path- way genes and activates Notch signaling}

We speculated that when activin $A$ induces various tissues from homogenous undifferentiated cells, Notch signaling is activated and plays some roles. To ascertain whether activin A induced Notch signaling, we examined the time course of the precise expression levels of Delta-1, Delta-2, Notch, and ESR-1 in animal caps after the treatment with activin $A$ using real-time RT-PCR. Animal caps were dissected from stage- 9 embryos and treated with $0,0.1,1.0,10$, and $100 \mathrm{ng} / \mathrm{ml}$ activin $A$ for 1 hour. The expression levels of Delta-1 (Fig. 1A), Delta-2 (Fig. 1B), and Notch (Fig. 1C) remained unchanged for 9 hours after the treatment with $0.1 \mathrm{ng} / \mathrm{ml}$ activin $A$. The expression levels of these genes increased with time from 3 hours after the treatment with more than $1.0 \mathrm{ng} / \mathrm{ml}$ activin A. The expression of Delta-1 and Delta-2 in the animal caps treated with $1.0 \mathrm{ng} / \mathrm{ml}$ activin $A$ increased approximately 6 - and 8 -fold at 9 hours, respectively, compared to the expression in untreated animal caps. Activin A at 1 and $10 \mathrm{ng} / \mathrm{ml}$ were more efficient in inducing Delta-1 and Delta-
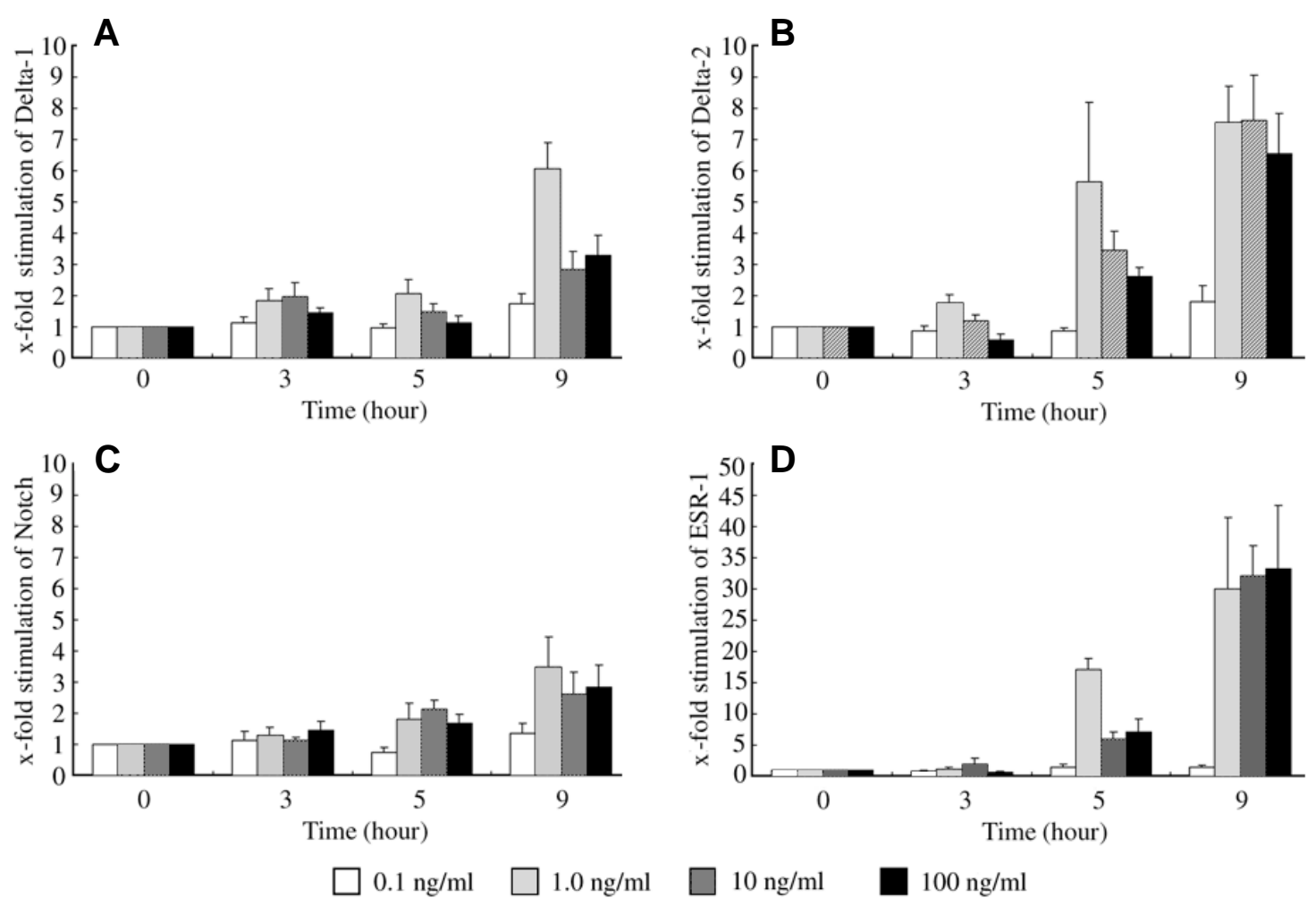

Fig. 1. Time course analysis of Delta-1, Delta-2, Notch and ESR-1 mRNA expression induced by activin A by real-time RT-PCR. RNA samples were derived from stage-9 animal caps which were treated with 0.1, 1.0, 10, and $100 \mathrm{ng} / \mathrm{ml}$ activin A for 1 hour, and then cultured for 3,5 and 9 hours. The expression levels of Delta-1 (A), Delta-2 (B), Notch (C) and ESR-1 (D) mRNA were quantified by real-time RT-PCR. The relative "stimulation fold" was calculated as the individual expression in activin A-treated animal caps relative to that in untreated animal caps at each developmental stage. The efficiency of CDNA synthesis from mRNA was assessed on the basis of real-time RT-PCR for ODC. The results represent the mean from three or four independent experiments, and error bars indicate the SEM. 


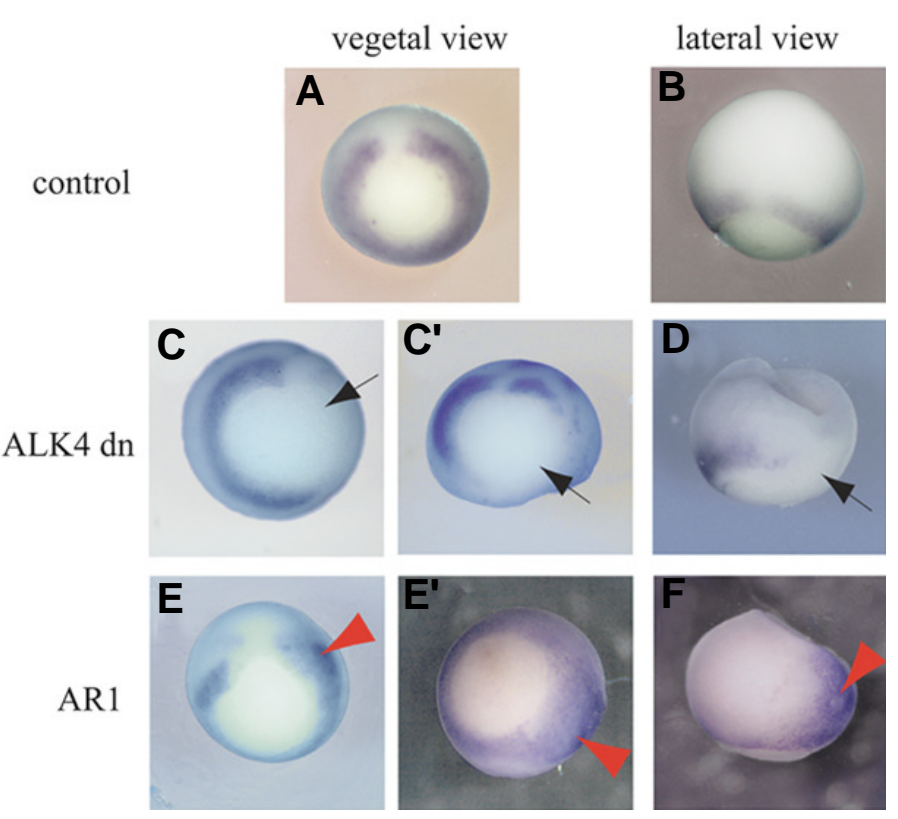

Fig. 2. The effect of Activin-like signaling on Delta-2 expression in vivo. The expression pattern of Delta-2 at stage 11 was examined by whole mount in situ hybridization. (A,B) Uninjected control embryos. (C,C',D) Embryos were injected with 500 pg of ALK4 dn mRNA into one blastomere at the 2- or 4-cell stage dorsally (C) or ventrally ( $\left.C^{\prime}\right)$. The injection of ALK4 $\mathrm{dn} m R N A$ suppressed the expression of Delta-2 on the injection side (black arrow). (E,E',F) Embryos were injected with 200 pg of ARI mRNA into one blastomere at the 2-or 4-cell stage dorsally $(E)$ or ventrally $\left(E^{\prime}\right)$. The injection of ARI mRNA increased the expression of Delta-2 on the injection side (red arrowhead). Vegetal views, dorsal at top $\left(A, C, C^{\prime}, E, E^{\prime}\right)$. Lateral views, animal pole at top $(B, D, F)$.

2 expression than treatment with activin $A$ at $100 \mathrm{ng} / \mathrm{ml}$. These results indicate that there is an optimal activin $A$ concentration for the induction of Delta-1 and Delta-2. Notch exhibited the same temporal expression pattern as Delta-1 and Delta-2. However, Notch expression in animal caps treated with $1.0 \mathrm{ng} / \mathrm{ml}$ activin $A$ increased only about 3-fold at 9 hours compared with untreated animal caps. The expression of ESR-1, a target gene of Notch signaling, increased at 5 hours in the animal caps treated with more than $1.0 \mathrm{ng} / \mathrm{ml}$ activin $\mathrm{A}$, and increased more than 30 -fold at 9 hours (Fig. 1D). The increase of ESR-1 expression ensured that activin $A$ could trigger Notch signaling. Together, these results indicate that concentrations of activin A higher than $1.0 \mathrm{ng} / \mathrm{ml}$ induce the expression of Notch-signaling member genes, and activate Notch signaling in animal caps.

\section{Activin-like signaling controls Delta-1 and Delta- 2 expres- sion in embryos}

The animal cap assay is a useful method to evaluate the effects and capacity of inductive signals in vitro, because its results likely mimic the inductive events occurring in vivo. To clarify whether activin-like signaling activates Notch signaling in vivo as it did in the animal caps, we investigated the expression of Delta-2 in embryos injected with wild-type activin type II receptor [AR1] (Hemmati-Brivanlou et al., 1992) or truncated (dominant-negative) activin type I receptor [ALK4-dn] (Chang et al., 1997). In stage-11 embryos, Delta-2 was expressed in a ring around the blastopore, with a gap in the most dorsal region (Fig. 2 A,B). The unilateral injection of ALK4-dn dorsally (Fig. 2C) or ventrally (Fig. $2 C^{\prime}$ ) at the 4-cell stage completely abrogated Delta-2expression on the injected side. In contrast, the unilateral injection of AR1 dorsally (Fig. 2E) or ventrally (Fig. 2E') at the 4-cell stage caused an increase in Delta-2 expression on the injected side, and its expression region expanded laterally (Fig. 2F). Similarly, Delta1 expression was blocked by the injection of ALK4-dn and increased by the injection of AR1 (data not shown). These results indicate that activin-like signaling induces Delta-1 and Delta-2 expression also in vivo, as seen in the animal caps. Furthermore, both dorsal and ventral expression of Delta-1 and Delta-2 are under the control of Activin-like signaling.

\section{MyoD induces Delta-1 expression but not Delta-2 expres- sion}

We showed that Delta-1, Delta-2, and Notch were expressed by 3 hours after activin A treatment, indicating that activin A may indirectly induce the expression of these genes. Wittenberger et al. reported that activin A induces MyoD expression and it in turn induces Delta-1 expression (Wittenberger et al., 1999). Then, we next examined whether MyoD can induced Delta-2 and Notch expressions in addition to Delta-1. Animal caps were dissected from MyoD-injected stage-9 embryos and expression levels of Delta-1, Delta-2, Notch, and ESR-1 were measured using realtime RT-PCR (Fig. 3A). The expressions of Delta-1 and ESR-1 in $M y o D$-injected animal caps increased approximately 8-fold compared to the expression in untreated animal caps. However, the expressions of Notch and Delta-2 in MyoD-injected animal caps were almost the same or slightly reduced compared to the expressions in untreated animal caps (Notch; 1.72-fold, Delta-2, 0.65 -fold). These results indicated that $M y o D$ induced Delta- 1 expression but did not induce Delta-2 and Notch expressions in animal caps.

In order to examine whether MyoD modulates Delta-1 and Delta-2 expressions in vivo, we investigated the expression of Delta-1 and Delta-2 in stage-11 embryos injected with MyoD.

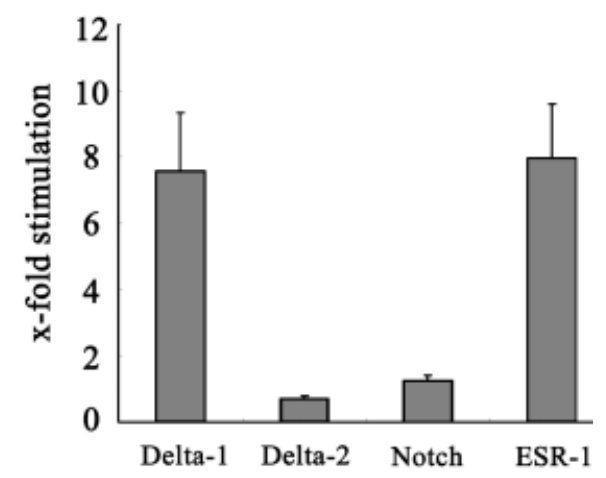

Fig. 3. The expression levels of Delta-1, Delta-2, Notch and ESR-1 in $M y o D$-injected animal caps. Animal caps were dissected from stage 9 embryos which were injected with 300 pg of MyoD mRNA into animal pole at 2-cell stage, and then cultured for 3 hours. The expression levels of Delta1, Delta-2, Notch and ESR-1 mRNA were quantified by real-time RT-PCR. The relative stimulation fold was calculated as the individual expression in MyoD-injected animal caps relative to that in untreated animal caps. The efficiency of CDNA synthesis from mRNA was assessed on the basis of real-time RT-PCR for ODC. The results represent the mean from three independent experiments, and error bars indicate the SEM. 

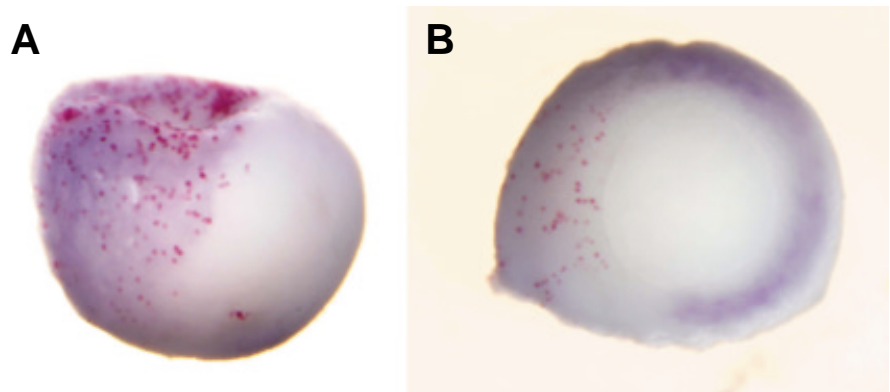

Fig. 4. The effects of MyoD injection on Delta-1 and Delta-2 expression in vivo. Embryos were injected with 1.0 ng MyoD mRNA together with 100 pg of lacZ mRNA as lineage tracer into one blastomere at the 2-cell stage. The expression pattern of Delta-1 (A) (lateral view) and Delta-2 (B) (vegetal view) at stage 11 was examined by whole mount in situ hybridization.

MyoDinjection increased Delta-1 expression, and ectopic Delta1 expression was seen in MyoD-injected area (Fig. 4A). In contrast, Delta-2 expression was decreased in MyoD-injected area (Fig. 4B). These results indicated that MyoDinduces Delta1 expression but inhibits Delta-2 expression in vivo.

\section{Discussion}

Activin and Notch signaling are both indispensable for proper early development. Activin-like signaling plays important roles in the induction of dorsal mesoderm during early embryogenesis. On the other hand, Notch signaling plays important roles when multipotent precursor cells achieve a specific cell fate. We speculated that during activin $A$ induces various tissues from homogenous undifferentiated cells, Notch signaling is activated and plays some roles. Our results revealed that, in animal caps, activin A induced the expression of Delta-1, Delta-2, and Notch, followed by the expression of ESR-1. The delay of ESR-1 expression compared with Delta-1, Delta-2, and Notchsuggested that activin A first induced Delta-1, Delta-2, and Notch expression, which activated Notch signaling, and then ESR-1 expression was induced (Fig. 5). Our real-time RT-PCR analysis showed that there is an optimal concentration of activin A for inducing Delta-1 and Delta-2. Activin A at intermediate concentrations (1 and $10 \mathrm{ng} / \mathrm{ml}$ ) was more efficient in inducing Delta-1 and Delta-2 expression than the lower- and higher-range concentrations $(0.1$ and $100 \mathrm{ng} /$ $\mathrm{ml}$, respectively). In stage-11 embryos, Delta-1 and Delta-2 are expressed in the marginal zone, in a ring around the blastopore. These findings suggest that the dose-dependent induction may

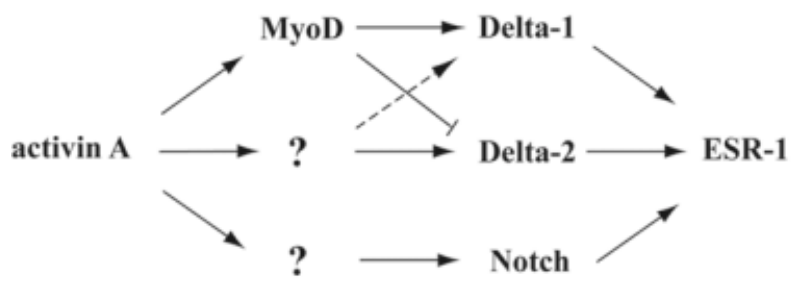

Fig. 5. Proposed model for the activation of Notch signaling induced by activin $A$. restrict expression area of Delta-1and Delta-2 in vivo. Concentration of activin-like signaling in the marginal zone may be at the appropriate level to induce Delta-1 and Delta-2 expression. We also demonstrated that activin-like signaling activates Notch signaling in vivo as it did in the animal caps. Injection of ALK4-dn completely abolished the expression of Delta-1 and Delta-2. These results imply that activin-like signaling is absolutely necessary and that no other signaling pathway can substitute for activinlike signaling to induce Delta-1 and Delta-2expression in the preinvoluted mesoderm. Delta-1, Delta-2and Notchwere expressed by 3 hours after activin A treatment, indicating that activin A may indirectly induce the expression of these genes. Wittenberger $e t$ al. reported that MyoD induces Delta-1 expression in Xenopus embryos, triggering the activation of Notch signaling (Wittenberger et al., 1999). We demonstrated in this study that in addition to Delta-1, activin A also induces the expression of Delta-2 and Notch. Furthermore, we demonstrated that MyoD can induce Delta-1 expression but can not induce Delta-2and Notchexpression. Notchexpression was neither induced nor inhibited by MyoD injection in stage-11 embryos (data not shown). To our surprise, MyoD inhibited Delta-2 expression in animal caps and in vivo. These results indicated that activin A induced Delta-1, Delta-2 and Notch by different cascade. Activin A may induce some protein besides $M y O D$, and it in turn may induce Delta-2and Notch expression (Fig. 5). We further speculated that the inhibition of MyoDmight alter Delta-1expression. Unfortunately, however, an antisense morpholino oligonucleotide against Xenopus MyoD(b) (MyoD MO) did not inhibit activin A-induced Delta-1 expression in animal caps and Delta-1expression shown in marginal zone (data not shown). MyoD MO may not inhibit MyoD functions completely because Xenopus laevisis psuedotetraploid species, having four copies of most genes. Otherwise, Delta-1 may be induced not only by $M y o D$ but also by some proteins induced by activin $A$, and they may compensate for the lack of MyoD function to induce Delta-1 (Fig. 5, dotted arrow).

In conclusion, we observed that activin A induced Delta-1, Delta-2 and Notch expression and activated Notch signaling. Furthermore, our results suggest that activin A induces Delta-1, Delta-2and Notch by different cascades. Not only MyoDbut also other activin A-induced proteins are involved in the activation of Notch signaling. We conclude that Notch signaling is activated when activin-like signaling induces various tissues from homogenous undifferentiated cells.

\section{Materials and Methods}

\section{Embryo manipulation}

Embryos were collected from Xenopus laevis females and artificially fertilized as previously described (Chan et al., 2000). The staging of embryos was according to the method of Nieukoop and Faber (Nieuwkoop and Faber, 1956). Embryos were dejellied by treatment with $4.5 \%$ cysteine hydrochloride in Steinberg's solution ( $\mathrm{pH} 8.0)$. Embryos were injected with mRNA in a volume of $10 \mathrm{nl}$ at the two- or four-cell stage in $5 \%$ Ficoll. Animal caps were dissected in $1 X$ Steinberg's solution $(\mathrm{pH} 7.4)$ and treated with 0.1 to $100 \mathrm{ng} / \mathrm{ml}$ Activin A.

\section{In vitro transcription}

Recombinant plasmids of pCS2-Notch $\Delta \mathrm{E}$ (Onuma etal., 2002), pSP6TtALK4 (Chang et al., 1997), p64T-XAR1-WT (Hemmati-Brivanlou et al., 1992), and pSP64T-MyoD(b) (Hopwood and Gurdon, 1990) were used as templates for the capped mRNAs. The capped mRNAs were synthesized 
in vitrousing the mMASSAGE mMACHINE T7 and SP 6 kit according to the manufacture's instructions (Ambion, Austin, TX). Digoxigenin-labeled antisense RNA probes were in vitro-transcribed with T7 and SP6 polymerase from template cDNA, for Delta-1, Delta2, and Notch (kindly provided from Dr. Kinoshita) using an RNA labeling kit according to the manufacturer's instructions (Roche Molecular Biochemicals).

\section{In situ hybridization}

Whole mount in situ hybridizations were performed according to the method of Harland (Harland, 1991) with an automatic in situ detection machine (InsituPro, ABIMED), except that the chromogenic reaction was done using BM purple as the substrate (Roche Molecular Biochemicals) and the RNase treatment was omitted.

\section{Real-time RT-PCR}

Total RNA was extracted from 6 to 10 animal caps by ISOGEN (Nippon Gene) according to the RNA extraction kit instructions. Random primed reverse-transcription was performed using $500 \mathrm{ng}$ total RNA as a template. Real-time PCR was performed on an ABI PRISM 7700 (Applied Biosystems) using SYBR Green PCR Master Mix (QIAGEN) according to the QuantiTect SYBR Green Kit instructions. The following primers were used ( $F$, forward; $R$, reverse):

Delta-1 F: 5'-AAGCCCAGGTACCCTTCTGT-3' R: 5'-GGCAGAGTCTGGTCGTCTTC-3'

Delta-2 F: 5'-TCTCACCTTGTCAGTGCCAG-3' R: 5'-AAAATGTTGCAGGATTTGCC-3'

Notch F: 5'-CCAACCGTGACATCACAGAC-3' R: 5'-GGAGCAGATGGGAGGTGATA-3'

ESR-1 F: 5'-TGGCAAAACTGGAACAGGAT-3' R: 5'-TGGGATACAACAGGGAGCTT-3'

ODC F: 5'-CAGCTAGCTGTGGTGTGG-3' R: 5'-CAACATGGAAACTCACACC-3'

\section{Acknowledgments}

We thank Dr. Y. Eto (Central Research Laboratories of Ajinomoto Co. Inc.) for providing us with human recombinant activin $A$, and $C$. Chang (The Rockefeller University, New York), A. Hemmati-Brivanlou (Harvard University, Cambridge), P. Bourillot (Wellcome/CRC Institute, Cambridge), J. Gurdon (Wellcome/CRC Institute, Cambridge) andM. Kinoshita (Kwansei Gakuin University, Hyogo) for their kind gift of plasmids. This work was supported in part by a grant-in-aid for Scientific Research from the Ministry of Education, Science, Sports, and Culture of Japan, and the Solution Oriented Research for Science and Technology Project of the Japan Science and Technology Corporation.

\section{References}

APELQVIST, A., LI, H., SOMMER, L., BEATUS, P., ANDERSON, D. J., HONJO, T., HRABE DE ANGELIS, M., LENDAHL, U., and EDLUND, H. (1999). Notch signalling controls pancreatic cell differentiation. Nature 400: 877-81.

ARIIZUMI, T., KOMAZAKI, S., ASASHIMA, M., and MALACINSKI, G. M. (1996). Activin treated urodele ectoderm: a model experimental system for cardiogenesis. Int J Dev Biol 40: 715-8.

ARIIZUMI, T., MORIYA, N., UCHIYAMA, H., and ASASHIMA, M. (1991a). concentration-dependent inducing activity of activin A. Roux's Arch. Dev. Biol. 200: 230-233.

ARIIZUMI, T., SAWAMURA, K., UCHIYAMA, H., and ASASHIMA, M. (1991b). Dose and time-dependent mesoderm induction and outgrowth formation by activin $A$ in Xenopus laevis. Int J Dev Bio/35: 407-14.

ARTAVANIS-TSAKONAS, S., RAND, M. D., and LAKE, R. J. (1999). Notch signaling: cell fate control and signal integration in development. Science 284: 770-6.

ASASHIMA, M., NAKANO, H., SIMADA, K., KINOSHITA, K., ISHII, K., SHIBAI, H., and UENO, N. (1990). Mesodermal induction in early amphibian embryos by activin A (erythroid differentiation factor). Roux's Arch. Dev. Biol. 198: 330-335.
BAILEY, A. M., and POSAKONY, J. W. (1995). Suppressor of hairless directly activates transcription of enhancer of split complex genes in response to Notch receptor activity. Genes Dev 9: 2609-22.

BRENNAN, H. C., NIJJAR, S., and JONES, E. A. (1999). The specification and growth factor inducibility of the pronephric glomus in Xenopus laevis. Development 126: 5847-56.

CHAN, T. C., TAKAHASHI, S., and ASASHIMA, M. (2000). A role for Xlim-1 in pronephros development in Xenopus laevis. Dev Bio/228: 256-69.

CHANG, C., WILSON, P. A., MATHEWS, L. S., and HEMMATI-BRIVANLOU, A. (1997). A Xenopus type I activin receptor mediates mesodermal but not neural specification during notch. Science 249: 1438-41. embryogenesis. Development $124,827-37$

COFFMAN, C., HARRIS, W., and KINTNER, C. (1990). Xotch, the Xenopus homolog of Drosophila notch. Science 249: 1438-41.

DE STROOPER, B., ANNAERT, W., CUPERS, P., SAFTIG, P., CRAESSAERTS, K., MUMM, J. S., SCHROETER, E. H., SCHRIJVERS, V., WOLFE, M. S., RAY, W. J., GOATE, A., and KOPAN, R. (1999). A presenilin-1-dependent gammasecretase-like protease mediates release of Notch intracellular domain. Nature 398: 518-22

DELFINI, M., HIRSINGER, E., POURQUIE, O., and DUPREZ, D. (2000). Delta 1 activated notch inhibits muscle differentiation without affecting Myf5 and Pax3 expression in chick limb myogenesis. Development 127: 5213-24.

FURUE, M., MYOISHI, Y., FUKUI, Y., ARIIZUMI, T., OKAMOTO, T., and ASASHIMA, $M$. (2002). Activin A induces craniofacial cartilage from undifferentiated Xenopus ectoderm in vitro. Proc Nat/ Acad Sci USA 99: 15474-9.

GREEN, J. B., and SMITH, J. C. (1990). Graded changes in dose of a Xenopus activin $A$ homologue elicit stepwise transitions in embryonic cell fate. Nature 347: 391-4.

HARLAND, R. M. (1991). In situ hybridization: an improved whole-mount method for Xenopus embryos. Methods Cel/ Bio/36: 685-95.

HEMMATI-BRIVANLOU, A., WRIGHT, D. A., and MELTON, D. A. (1992). Embryonic expression and functional analysis of a Xenopus activin receptor. Dev Dyn 194: 1-11.

HITOSHI, S., ALEXSON, T., TROPEPE, V., DONOVIEL, D., ELIA, A. J., NYE, J. S., CONLON, R. A., MAK, T. W., BERNSTEIN, A., and VAN DER KOOY, D. (2002) Notch pathway molecules are essential for the maintenance, but not the generation, of mammalian neural stem cells. Genes Dev 16: 846-58.

HOPWOOD, N. D., and GURDON, J. B. (1990). Activation of muscle genes without myogenesis by ectopic expression of MyoD in frog embryo cells. Nature 347: 197-200.

LECOURTOIS, M., and SCHWEISGUTH, F. (1995). The neurogenic suppressor of hairless DNA-binding protein mediates the transcriptional activation of the enhancer of split complex genes triggered by Notch signaling. Genes Dev 9 : 2598-608.

LEIMEISTER, C., EXTERNBRINK, A., KLAMT, B., and GESSLER, M. (1999). Hey genes: a novel subfamily of hairy- and Enhancer of split related genes specifically expressed during mouse embryogenesis. Mech Dev 85: 173-7.

MCCRIGHT, B., GAO, X., SHEN, L., LOZIER, J., LAN, Y., MAGUIRE, M., HERZLINGER, D., WEINMASTER, G., JIANG, R., and GRIDLEY, T. (2001). Defects in development of the kidney, heart and eye vasculature in mice homozygous for a hypomorphic Notch2 mutation. Development 128: 491-502.

MCLAUGHLIN, K. A., RONES, M. S., and MERCOLA, M. (2000). Notch regulates cell fate in the Development developing pronephros. Dev Bio/227: 567-80.

MORIYA, N., KOMAZAKI, S., TAKAHASHI, S., YOKOTA, C., and ASASHIMA, M. (2000). In vitro pancreas formation from Xenopus ectoderm treated with activin and retinoic acid. Growth Differ 42: 593-602.

MORIYA, N., UCHIYAMA, H., and ASASHIMA, M. (1993). Induction of pronephric tubules by activin and retinoic acid in presumtive ectoderm of Xenopus laevis. Dev Growth 35: 123-128.

MUMM, J. S., SCHROETER, E. H., SAXENA, M. T., GRIESEMER, A., TIAN, X PAN, D. J., RAY, W. J., and KOPAN, R. (2000). A ligand-induced extracellular cleavage regulates gamma-secretase-like proteolytic activation of Notch1. Mol Cel/5: 197-206.

NIEUWKOOP, P. D., and FABER, J. (1956). Normal table of Xenopus laevis (Daudin). Amsterdam: North-Holland. 
NOFZIGER, D., MIYAMOTO, A., LYONS, K. M., and WEINMASTER, G. (1999). Notch signaling imposes two distinct blocks in the differentiation of $\mathrm{C} 2 \mathrm{C} 12$ myoblasts. Development 126: 1689-702.

ONUMA, Y., TAKAHASHI, S., ASASHIMA, M., KURATA, S., and GEHRING, W. J. (2002). Conservation of Pax 6 function and upstream activation by Notch signaling in eye development of frogs and flies. Proc Nat/ Acad Sci USA 99: 2020-5.

OSAFUNE, K., NISHINAKAMURA, R., KOMAZAKI, S., and ASASHIMA, M. (2002). In vitro induction of the pronephric duct in Xenopus explants. Dev Growth Differ 44: $161-7$.

RONES, M. S., MCLAUGHLIN, K. A., RAFFIN, M., and MERCOLA, M. (2000). Serrate and Notch specify cell fates in the heart field by suppressing cardiomyogenesis. Development 127: 3865-76.
TANNAHILL, D., BRAY, S., and HARRIS, W. A. (1995). A Drosophila E(spl) gene is «neurogenic» in Xenopus: a green fluorescent protein study. Dev Biol168: 694-7.

WitTENBERGER, T., StEINBACH, O. C., AUTHALER, A., KOPAN, R., and RUPP, R. A. (1999). MyoD stimulates delta-1 transcription and triggers notch signaling in the Xenopus gastrula. EMBO J18: 1915-22.

Received: March 2004 Reviewed by Referees: April 2004 Modified by Authors and Accepted for Publication: May 2004 Edited by: George M. Malacinski 